\title{
CLINICAL INVESTIGATION OF XEROPHTHALMIA AND DYSTROPHY IN INFANTS AND YOUNG CHILDREN (XEROPHTHALMIA ET DYSTROPHIA ALIPOGENETICA).
}

\author{
By C. E. BLOCH, M.D., \\ Professor of Pediatrics in the University of Copenhagen.
}

(With Plates II-IV and 5 Charts.)

\section{Preface by the Accessory Food Factors Committee (appointed jointly by the Lister Institute and the Medical Research Council).}

THe investigations of Professor Bloch upon xerophthalmia in infants and young children are of unusual interest when considered in conjunction with the experimental production of the disease in rats by a deficient diet. The history of Professor Bloch's researches is particularly instructive. The first cases of xerophthalmia in infants only. came under his notice in the Children's Department of the State Hospital in Copenhagen, after they had been under (unsuccessful) treatment in the Ophthalmic Department of the same institution. It was noticed in many instances that the children showed signs of general malnutrition in greater or less degree and it was while giving attention to this aspect of his cases that Professor Bloch discovered the striking curative effect upon the eye disorder of giving a diet rich in fat, e.g. full milk and especially cod-liver oil. Later, on becoming acquainted with the experimental work upon xerophthalmia caused in rats by a deficiency of the "fat-soluble" accessory factor, he was able to devise a treatment consisting solely of addition to the diet of cod-liver oil, as was carried out in the eight cases in the Copenhagen Children's Home, described below.

Professor Bloch's work was published in Danish in 1917 and 1918 and was therefore not available for the majority of English readers. The Committee on Accessory Factors therefore undertook the publication in English of an abridged translation of two of the later papers, to which Professor Bloch has added a short account of his experience in 1918 and 1919. In the meantime the more important of these papers, but without photographs, has appeared in the Jahrbuch für Kinderheilkunde (1919), vol. LxxxIx.

The Committee desires in this place to record its thanks to Dr Thaysen and to Dr E. E. Atkin, by whom the English translations were made. 
Xerophthalmia is considered a rare disease. Only amongst the negro slaves of Brazil and amongst the poorest and most ignorant inhabitants of Russia is it said to have been observed to any extent. The disease is generally described as follows: the first symptoms are dryness of the ocular conjunctiva, which becomes wrinkled and shrunken. Later on small yellowish white spots appear, as though the conjunctiva had been dotted with paraffin wax. At this stage the disease is termed xerosis conjunctivae. The dryness rapidly spreads over the whole conjunctiva and over the cornea, which becomes dull, uniformly hazy and insensitive. Later the cornea turns greyish and still later yellowish, until at last a more or less extensive necrosis of the cornea sets in, followed by ulceration (keratomalacia). The necrosis and ulceration may appear in the course of a few hours.

It is characteristic of the disease that there is hardly any reaction in spite of the far-reaching changes in the eye; lachrymation, photophobia and spasm of the eyelids are absent. In the beginning no injection or ulceration of the mucous membrane is seen, and no secretion takes place. A very striking contrast thus exists between the severe and mild types of the disease.

All authors agree that the keratomalacia is due to insufficient nutrition of the cornea, and that this again is a consequence of the disorganisation of the whole mechanism of nutrition. The disease therefore only occurs amongst children who have been ailing for a considerable time, and is often met with amongst infants who have been insufficiently nourished. Especially it is observed after prolonged diarrhoea, and debilitating diseases, such as typhoid fever, scarlatina, hereditary syphilis, etc.

My own material comprises 40 cases from 1912-1916 and 23 cases from 1917 onwards, all of which have occurred amongst children treated in the children's section of the State Hospital.

Of the 40 cases in 1912-1916 five showed xerosis alone; in the other 35 cases the cornea was attacked, 28 cases showing keratomalacia of both eyes and seven cases of one eye only. In many cases the necrosis of both corneae was complete. There was ulceration of the cornea in nearly all, several showing prolapse of the iris, and a few, extrusion of the lens. My material thus comprises mainly severe and serious cases of this disease.

The actual effect on the eye will not be discussed in further detail. There is only one point which I should like to draw attention to, because my cases exhibit certain aspects, which do not entirely agree with earlier observations. Only in three cases of xerosis and three cases of keratomalacia were the lesions slight. The eye condition in these cases was of minor importance compared with the other symptoms. Those associated with the children had hardly noticed that the eyes were abnormal. Only on examination at hospital were the eyes found to be affected and the disease must therefore have taken a very acute course. These cases are almost identical with those described by other authors. They all occurred in miserably emaciated children, only a few months old. In none of the cases did the keratomalacia reach its climax 
with extensive ulcerations and gangrene. The children died from marasmus and its complications before this stage was reached.

In all the other cases examined by me there were marked lesions of the eyes, contrary to what had been observed before. In many cases the damage was extraordinarily extensive, and it was generally the irritation of the eyes that had induced the parents to seek medical advice. Lachrymation and photophobia were generally given as the first symptoms, but injection, ulceration and abundant discharge from the eye were also observed. In addition there was also spasm of the eyelids. Most cases thus showed both xerophthalmia and conjunctivitis. The course of the eye complaint could be followed by comparing the various patients, or the two eyes of one and the same patient; as the disease could often be found in different stages in the two eyes.

The first change obviously had been xerosis of the conjunctiva. The children felt that something was wrong and perhaps they could not see so well as before. They would therefore begin rubbing their eyes and the parents have often noticed this. This rubbing caused conjunctivitis, and its accompanying photophobia and discharge from the eyes. Gradually the discharge grew worse and this generally led the parents to seek medical advice.

In many cases the conjunctivitis appeared in addition to general catarrhal infection. The first sign that the child was unwell was a cold but the eyes continued to discharge after the cold had disappeared, and the condition grew worse.

In an isolated case the eye complaint appeared simultaneously with measles, and the doctor paid little attention to it. Only when the measles had disappeared and the eye trouble steadily grew worse did it become clear that it was due to something else. In the meantime, however, both corneae had been completely destroyed by necrosis.

In all these cases the eye lesion was only part of the disease. The constitution of the patients had been undermined, as was visible from the abnormal appearance of the children. The change was noticeable in various ways, from which three distinct types stand out, with practically every intermediate form. Two of these types are identical with the complaints described by Czerny and his co-workers under the name of "Mehlnährschaden." I term these two types: carbohydrate atrophy and carbohydrate dystrophy respectively. Pronounced cases of the third type were markedly different from the two others, as no atrophy, oedema or hypertonicity of the muscles were found, which are particularly characteristic of Types 1 (Pl. II, fig. 1) and 2 (Pl. II, fig. 2). Furthermore, these children had not had an excess of carbohydrate as had been the case with the others. 


\section{Type III. Xerophthalmia and Dystrophia alipogenetica.}

This third group showed the least pronounced characteristics (Pl. II, fig. 3). At first sight the children seemed almost normal apart from the eye complaint, and one doubted whether any constitutional derangement existed. On closer examination, however, the children bore marked signs of a general breakdown in health. They were all very backward in their development and they were weak and thin, and markedly anaemic. When left to themselves they were apathetic and took no interest in their food. The older ones were hypersensitive to external impressions. They were as susceptible to secondary infections as the children showing marked dystrophy and atrophy.

The clinical information available clearly showed that these children had long been on an unsuitable and insufficient diet consisting of centrifuged milk, milk puddings made with this separated milk, and some of their parent's low diet, such as potatoes, bread, etc. The cause of the disease and particularly of the eye complaint was evidently not due to an excess or deficit of carbohydrate nor could it have been caused by the absence of protein, salts, or water-soluble vitamines as all of these substances were present in sufficient quantities in the children's food.

When I published my first paper it was unknown in this country that the American physiologists had obtained evidence of the presence of certain specific bodies in various fats.

None of my cases had received fresh milk for any length of time. They were all cured by cod liver oil and improved by fresh milk. I therefore attributed the disease to the absence of some sort of fat. This assumption was supported by observations made by Mori in Japan on a disease called hikan; which in many respects resembled my third type. The Japanese disease was considered to be due to the absence of fat in the food. My observations, however, have made it clear that the disease was not due to the absence of fat as such, but probably to the absence of certain bodies normally present in butter fat and in large quantities in cod liver oil. I therefore proclaimed that the disease was most probably due to "the absence of specific lipoid bodies or their constituents" by which I meant to include all the possibilities. Since I considered that the stunted growth and general ill health as well as xerophthalmia were caused by lack of these substances, I called the disease Dystrophia alipogenetica to distinguish it from carbohydrate atrophy and I applied the same designation to xerophthalmia.

Since that time I have become acquainted with the experiments carried out on growth of young rats by McCollum and his co-workers and Osborne and Mendel.

From experiments carried out by McCollum and his collaborators, it appears that a fat free diet inhibits the growth of young rats and some time later their eyes become diseased: If this diet is continued the animals die. Later experiments have shown that these abnormalities were not due to the 
absence of fats but to lack of a certain specific substance called "Fat soluble A," which is present in certain fats only. So far the substance has been found in milk and butter fat, egg yolk fat, and in the ether extract of kidneys and testes, in beef fat and in cod liver oil. As regards vegetable fats it has been found in small quantity in the wheat germ and in the ether extract of maize, but not in olive oil, cotton seed oil or almond oil. Pork fat or suet, in the condition in which these substances are sold in the markets, contained quantities inappreciable by their experiments.

The actual nature of the body is unknown. It has been found to be comparatively resistant and is not destroyed by boiling for a short time although it does not stand prolonged boiling or being heated to higher temperatures. It is also probable that it is rendered inactive by the various methods of purification and preservation resorted to, and this is possibly the reason why it has not been found in many of the fats sold in the shops.

Young rats fed on a diet containing fats of this latter type show the same pathological changes as are caused by the absence of fats. The first case where xerophthalmia was noticed in young rats occurred after a prolonged diet of protein-free milk, starch, and pork fat (Osborne and Mendel (1913-14)). The eye trouble is described as inflamed eyes gradually becoming purulent. When taken in time it was possible to cure the animals by feeding with butter fat or cod liver oil. Osborne and Mendel thus mention that a small quantity of cod liver oil given in lieu of pork fat is sufficient to restore the weight and cure the disease. The eyes rapidly become normal.

Thus it will be seen how close is the agreement between the experiments on anımals and my previously published clinical observations. A prolonged unvaried diet, containing either no fats or no specific lipoid bodies (as far as children are concerned, lack of fresh milk), causes both children and rats to fall sick. In both cases the disease manifests itself first and foremost as a constitutional disturbance expressing itself as inhibited growth and loss of weight, a condition which I have termed dystrophy. In a number of cases eye trouble develops; at first the eyes are inflamed and later become purulent and necrotic. If the diet is persisted in, both children and animals die. In both cases the dystrophy and the eye lesions can be cured by administration of cod liver oil and butter fat.

During the year 1917 I again observed and treated numerous cases of these diseases. My new material has brought certain points to light and has confirmed and extended my already published contributions. Keeping in mind the results of the experiments on animals, it has been comparatively easy to deal with this additional material as knowledge has now been acquired concerning points which were previously difficult to interpret.

My cases of xerophthalmia in 1917 were 23 in number and exhibited a somewhat altered character, there being not only the extremely serious cases of keratomalacia, which predominated in earlier years, but also a large 
number of milder cases. Of the 23 children, 11 had eye trouble for a few weeks before the real nature of the disease was discovered; these cases occurred amongst somewhat older children. As far as the eyes were concerned xerosis was the only lesion. Amongst my previous material there were no such cases.

Eight of the milder cases came from a Home for children in Copenhagen in the administration of which I take part. Six of these had been in the Home for more than a year and had developed well before the present illness so that they may be considered as originally healthy children. As the conditions giving rise to the disease are fairly well known in these instances, they may be considered as straightforward and simple as the animal experiments.

In this Children's Home there were 86 children separated into two sections, each with its own building. Section A comprised the infants and as far as possible, the delicate and sick children. The healthy children or those more than a year old were in Section B. Both sections were again divided into two subsections completely isolated from one another. Section B contained 32 children, 16 in each subsection, B I and B II. The eight cases of xerophthalmia occurred in the same subsection, B I, so that half the children in this subsection of the hospital were attacked. They fell ill almost simultaneously during May and the beginning of June. In none of the other subsections was the disease observed and no further cases have appeared in subsection B I.

There was no initial difference between the children of the two subsections, B I and B II; their ages and conditions of health were very much alike. The hygienic conditions were identical and everywhere excellent. The diet, however, was different inasmuch as the infants and the delicate children of Section A had chiefly whole milk, and puddings made of it. The older children in Section B had received a more varied diet; oatmeal gruel with moks or "ollebröd" (beer-and-bread soup) with a little fresh milk for breakfast. The midday meal consisted of milk pudding, sometimes made with buttermilk, oatmeal gruel, soups made with fruit juice and sometimes meat broth with pearl barley. As second course they had boiled fish, minced meat and a good helping of mashed potatoes. In the afternoon the children had cocoa with bread and margarine and in the evening milk pudding and bread and margarine. The margarine was made from vegetable fats and all the food was prepared with this vegetable margarine. The children were never given butter or eggs nor was cream or fresh milk ever used in the preparation of their food. The milk used consisted of half-skimmed milk. The only whole milk the children had was the small quantity given in the morning with the breadand-beer soup.

The breakfast was somewhat different in the two B subsections. The matron of B II had given the children under her care beer-and-bread soup with whole milk, while the children of B I, where the xerophthalmia appeared, had had oatmeal gruel and rusks, so that these latter children had not had 
whole milk for several months. The choice between these diets was left to the matrons' discretion, the rule being that children with a tendency to diarrhoea must not have bread-and-beer soup.

All the children were weighed regularly, the infants (Section A) once a week, the older children (Section B) every fortnight. The weighing always took place at the same time of the day, just before their last meal. As the weighing was done in the afternoon the results are not quite reliable. The amount of food the children had consumed, their activity and the quantity of sweat lost during the day must have affected the result. Another disturbing factor is that the weighing was rather infrequent. On the other hand it was always controlled by the same trained nurse and done at the same time and with the same scales. Care was also taken that as far as possible the children had emptied the bladder and rectum, so that the results undoubtedly gave a rough idea of the growth of the children.

The results obtained indicate that most of the children of Section A, who got whole milk, developed normally during the winter 1916-17 and the spring of 1917. Amongst the 32 children of Section B there were quite a number who only slowly put on weight during the winter; $15 \mathrm{kept}$ their weight unchanged during winter and spring, while some of them even lost in weight, particularly during April and May. Of the 15 children five belonged to subsection B II and ten to B I. The eight cases of xerophthalmia occurred amongst the latter ten. The ages of these children varied from $1 \frac{1}{2}$ to 4 years. The cases are illustrated by the curves on p. 290.

The xerosis was very marked in all eight cases and had generally been present for some time probably for a couple of weeks before it was recognised. The first symptom was photophobia, the eyes became red and in some cases there was a slight sticky secretion. At first it was taken for a mild conjunctivitis, and treated with zinc drops. As this did no good and the eyes became worse, a more careful examination was made which made it clear that the children were suffering from xerosis. In some of the cases the xerosis was quite recent without general injection of the conjunctivae and in only two cases was there slight dryness of the corneae.

Apart from two cases one would undoubtedly, after a superficial examination, have considered these children quite normal. A more careful investigation, however, would have shown that they had been rather weak for some time and had lost their appetite. Their curves showed that six cases had remained constant in weight during the whole of the winter and that four cases had lost weight considerably during April and May, some time before the eye complaint was discovered (see Charts 1, 2 and 3).

Malling-Hansen's well-known investigations on the weight of children at the Deaf and Dumb Institute have shown that normal children during the ages of 9-15 years generally remain constant in. weight or decrease slightly during the months of April, May and June. The loss of weight found in my cases during the spring has probably, to some extent, the same cause as that 
noticed by Malling-Hansen. It is quite a common phenomenon that the change from indoor life to a life in the open air for most of the day is accompanied by a loss in weight which is soon compensated during the summer.

However, the loss of weight in my series of cases was greater than

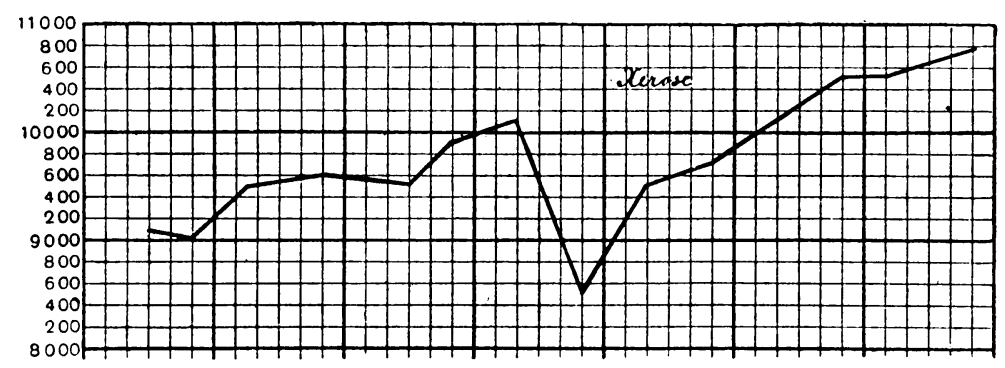

Chart 1. Weight record of Allis, born 2. vi. 1915. Admitted 24. v. 1917. Has been very ill with measles during the summer 1916. Since then she has developed fairly well but has lately again lost weight.

On 23. v. 1917. Xerosis conjunctivae of both eyes beginning. Cod liver oil-xerosis disappears and the child increases in weight.

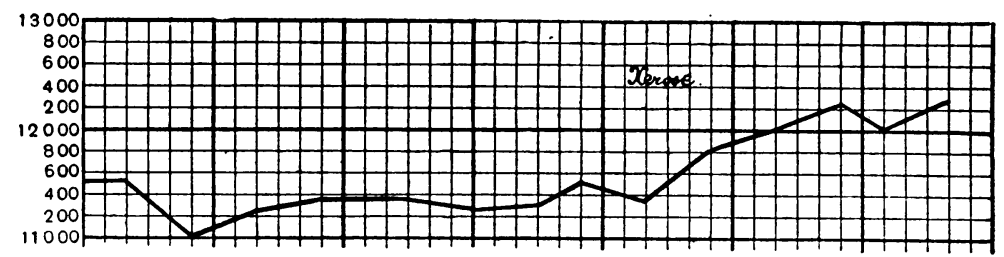

Chart 2. Weight record of Sigurd, born 19.x. 1915. Admitted 13. xii. 1915. Developed fairly well up to the winter 1916. Since then no increase but frequent attacks of catarrh.

On 23. v. 1917. Slight xerosis of conjunctivae of both eyes. Cod liver oil-xerosis disappears and the child increases in weight.

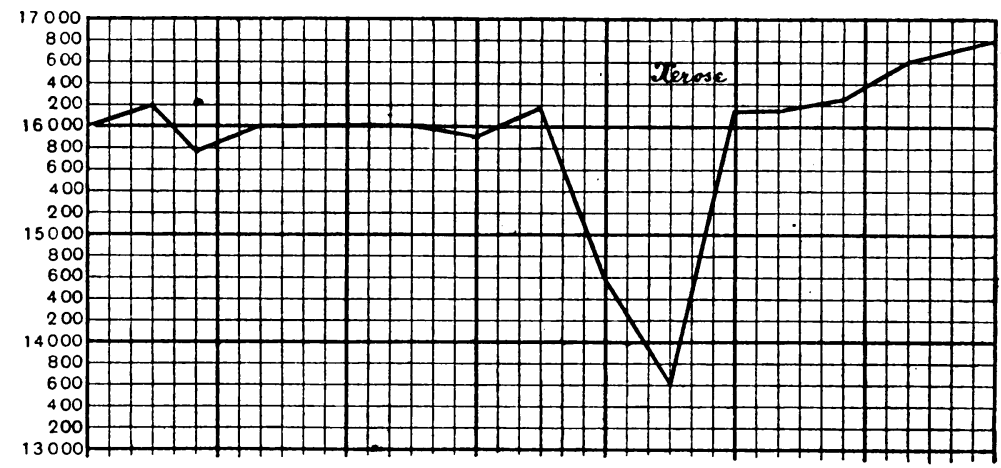

Chart 3. Weight record of Hulda, born 13. ii. 1913. Admitted 1. ix. 1913. She developed normally up to the winter 1916. Since then her weight has remained stationary.

On 23. v. 1917. For about a week she has been suffering from photophobia, has had purulent eyes and been treated for this with solutions of zinc. At present marked xerosis of conjunctivae of both eyes. Cod liver oil-xerosis disappears and the child increases in weight. 
ordinarily takes place. It was also abnormal that the children's weight should have remained constant during the whole of the winter and spring when they were kept on a good diet and allowed to eat as much as they wanted. The loss or constancy in weight can only be explained as an inhibition of growth.

In spite of the loss of weight and the xerosis, it was decided to keep the children on exactly the same diet as before. Only the two children whose eyes were in the worst condition, were kept in bed for a few days. The others remained up and out of doors as before. The only treatment employed, in fact the only change in their mode of life, consisted in giving $10 \mathrm{gms}$. of cod liver oil twice a day. The children liked the oil and the effect was even more marked than in any of my earlier cases where the disease had progressed much further. In the course of a few days the xerosis became less and disappeared completely in a week. At the same time the children became livelier and those of them who had remained constant in weight for some time, began growing again. The curves clearly show the effect of the daily dose of 20 gms. of cod liver oil. In July the whole diet of the children was changed; but up to that time in spite of the same food as before, no more cases of xerophthalmia occurred.

It will be seen that the children behave much as the animals in the experiments of the American physiologists. They first stop growing and then lose weight. This is the initial stage which I have termed dystrophy. Then comes the eye trouble. The latter is therefore only a sign of a general pathological condition.

The reason for this is clear. The children who had plenty of fresh milk developed normally but amongst those who had only a trifling amount were several who did not thrive at all and some who lost weight, and many of them got bad eyes. Instead of whole milk these children had had "half-skimmed milk," i.e. centrifuged milk with the addition of enough of whole milk to make the fat content of the mixture 0.75 per cent. Both the whole milk and the "half-skimmed" milk had been pasteurised at the dairy and in addition both were boiled at the hospital before being given to the children.

As far as our knowledge went at that time the food given to the children in the Home was good and nutritious. The diet was sufficiently varied and contained plenty of protein, fat, carbohydrate and salt. It must also have been rich in water-soluble vitamines, on account of the liberal supply of potatoes and fruit juices. We now know that a mistake was made in not supplying the proper fats, i.e. fats in which the specific bodies are contained. As soon as these substances were supplied in the form of cod liver oil, the diet became a suitable one and the children thrived and the eye trouble disappeared. Our experience thus shows that vegetable margarine is unable to replace butter, and that it is important the children should be given whole milk.

Since July, 1917, the skimmed milk has been partly replaced by whole milk in the Children's Home. The children are now thriving better and that 
their condition of health has improved. No further cases of xerophthalmia have occurred.

Of nine similar cases from the State Hospital, of ages varying from 9 months to 10 years, all showed xerosis conjunctivae. In four of the cases the cornea had not yet been attacked and with respect to the eye the disease was in its initial stage. The children had only recently had bad eyes, red and discharging, and developed photophobia. In three of these four cases night blindness could be demonstrated, a symptom which appears very early in the disease but was not noticed in any of my earlier cases, either because the children were too small, or because the lesion of the cornea was so extensive as to mask it. These cases and those from the Children's Home described above show that xerosis of the conjunctiva may exist for a long time without spreading to the cornea. In this early stage the complaint resembles an ordinary conjunctivitis, the eyes often being red, discharging and showing photophobia. Much conjunctivitis, however, appears later and generally in children which are suffering from catarrh.

In the remaining five cases the cornea was attacked, in three cases with keratomalacia of one eye, two of which displayed complete necrosis of the cornea; in two cases with keratomalacia of both eyes. The children were very backward, weighed less and were much smaller than normal children. They were weak and anaemic and many of them seemed to behave in a peculiar manner to infections, particularly catarrhal infections of the mucous membranes and infections of the urinary tract. Six of the nine children had catarrhal infections, two of them, broncho-pneumonia, and three, pyuria. I intend to return to this point later. Not only were the children weak in body but their minds were also affected. In the early cases the children were quieter than usual and had lost their appetite. In the more advanced cases they were extremely sensitive to external stimuli. This may have been partly due to the eye complaint but, no doubt, was mainly caused by the malnutrition. In my previous articles I have termed this condition psychic hyperaesthesia. This extreme sensitiveness has nothing to do with the nervous symptoms met with in convulsions nor with the "hypermotility" described by Czerny as characteristic of incipient "Mehlnährschaden." I have found neither of these symptoms occurring in this kind of dystrophy (alipogenetica) or in carbohydrate dystrophy.

The above cases illustrate the condition described in my earlier paper as the third type of xerophthalmia. The first sign seems to be merely an inhibition of growth passing into dystrophy, of a type found amongst children who have been fed chiefly on separated milk for some time. Amongst these cases were three which had had whole milk for a long time and one had even been given cream, yet they all had xerophthalmia and the three had marked dystrophy just like the children fed mainly on centrifuged milk. These cases do not 
agree altogether with my previous experience. The explanation must evidently be sought in the animal experiments of the American physiologist who found that the specific bodies dissolved in milk fat are easily destroyed. In the three cases under consideration the whole milk was first mixed either with centrifuged milk or with water or oatmeal gruel and then boiled for a considerable time. The cream given in one case was the so-called "export cream," specially prepared and sterilised in order to preserve it. These cases were cured in exactly the same way as all the others by administering the specific bodies in the form of cod liver oil and whole milk.

All the above cases lead to the conclusion that xerophthalmia, inhibition of growth and dystrophy, are due not to the absence of water-soluble vitamines or of fats but to the absence of the specific bodies present in certain fats.

\section{Type II. Xerophthalmia with Carbohydrate dystrophy.}

Among the 23 cases of xerophthalmia treated in 1917 were six cases displaying the same clinical picture as those described by Czerny-Keller under the name of "Mehlnährschaden." Nearly all of them belong to the form, which, in an earlier paper, I described under the name of carbohydrate dystrophy. The diet of these children had for a long time been very uniform and consisted mainly of carbohydrates. All the children were infants, only one was more than 12 months old. Three of them were less than six months. All the children were backward in development. They had lost their appetites, and were fretful and sensitive to outside impressions when they had not been rendered apathetic by the ravages of the disease. They were nearly always anaemic and most of them frequently suffered from catarrh. Two had bronchopneumonia and four had pyuria. The eye complaint was far advanced in all the cases. The corneae were always attacked, in one case with complete necrosis of one cornea and in another (which died) with complete necrosis of both corneae.

All these cases showed the symptoms characteristic of carbohydrate disease. This was not so with the cases previously described. The tissues were oedematous and the children had the appearance of being blown out. There was also muscular rigidity which was so pronounced in three of the cases as to constitute the characteristic muscular hypertonicity (see Pl. II, figs. 1 and 2). The usual treatment with cod liver oil and with whole milk or human milk caused all symptoms to disappear.

The question now is, what is the aetiology of the oedema and hypertonicity of the muscles? These symptoms cannot be ascribed to the absence of the specific lipoid bodies as they did not occur in the other cases where the disease was due to this cause. It might perhaps be suspected that the oedema was caused by the inability of the patients to excrete the necessary quantities of salts. This assumption, however, is incorrect, as all the patients were able to excrete salts to the normal extent. It is more reasonable to associate the oedema and the hypertonicity with the excessive supply of carbohydrates 
and the simultaneous almost complete absence of fats, the points in which these cases differ markedly from the others. It must not be forgotten, however, that the oedema and hypertonicity may be due to the absence of quite different vitamines or of other specific bodies. In that case the whole clinical picture included in "Mehlnährschaden" would come under Casimir Funk's so-called "Avitaminoses" if the particular lipoid bodies were classed as vitamines.

The case quoted below may possibly throw some light on this question.

Ernst, 4 years old. Son of a bricklayer. Admitted to hospital 14. ii. 1914; discharged 29. iv. 1914.

During the last two years the patient's evacuations have had a tendency to be frequent, thin and slimy. He has repeatedly been on constipating diet for a considerable period but without appreciable effect. There has never been blood in the evacuations and the patient has never suffered from constipation. He has always been very keen on eating potatoes and has also had an inclination to eat gravel, soil and paper. The mother thinks he has a longing for these things, he has been known for example to peel the plaster off the walls and eat it.

During the last six weeks his condition has become worse. He has had as many as 10-20 thin, slimy and greenish evacuations daily. Both faeces and urine are often passed involuntarily. In the last few days oedema of the eyelids and legs has appeared. All this time he has been kept in bed on a diet consisting of oatmeal gruel, bread and mashed potatoes. He has eaten a great deal and during most of his illness has been on a milk-free diet.

On admission he was very wasted. There was cyanosis of the hands, and the mucous membranes were pale. There was extensive general oedema of the subcutaneous tissue especially of the face. The eyelids were so oedematous that the eyes were almost closed. There was also considerable oedema of the extremities and loins. There was a considerable amount of ascites. The urine was normal.

The patient was treated with tea, oatmeal gruel, boiled milk, acorn cocoa, and milk pudding. The motions, which previously were slimy, thin and green, and had a sour odour, improved and the bowels acted normally a fortnight after entering hospital. Simultaneously the oedema disappeared giving rise to a loss of about $1 \mathrm{~kg}$. in weight. After this the patient speedily recovered and he put on $2.5 \mathrm{~kg}$. in weight.

In this case the oedema had appeared after prolonged feeding with carbohydrates and potatoes. Perhaps this combination of foodstuffs accounted for the unusually marked and widespread character of the oedema. I have never before seen it so extensive after a carbohydrate diet. The child must have been supplied with large quantities of water-soluble vitamines in the potatoes so that the oedema cannot be ascribed to the absence of these bodies. Since a lack of the specific lipoid bodies is not known to cause oedema it is probable that the absence of the fats in addition to the liberal supply of 
carbohydrates, may have been the cause. At all events it disappeared in this case when the amount of carbohydrate was reduced and replaced by fats in the form of boiled whole milk.

Complaints similar to the above have so far been little known in adults. During the war, however, there have been epidemics of dropsy, the so-called war-oedema, occurring in places where famine was reigning and in the large prisoners' camps in Germany. As far as is known this disease is associated with similar symptoms and arises in connexion with the same conditions of diet. Concerning the aetiology of this war-oedema nothing so far is known beyond the fact that it is connected with a deficient diet, but probably similar causes to those in the case of children are operative.

\section{Notes on Treatment.}

The treatment of all the cases has been identical with that described in my earlier papers.

The local treatment of the eyes has generally been confined to frequent washing with sterile water, when there was marked conjunctivitis. In cases of xerosis, sterile vaseline was applied. When the cornea was attacked and there was danger of necrosis or when ulceration had already appeared, atropin drops were used. In two cases it was necessary, on account of panophthalmia, to remove one of the eyes.

The chief aim has always been to improve the children's general condition of health by supplying them with the necessary bodies which had been absent from their food. As before, cod liver oil was found to be a specific cure for the disease. Its effect was always very marked, but most striking in the early stages of the complaint. The eyes improved within a few days and became quite normal after about a week's treatment. The loss of weight was simultaneously arrested and the children generally began to thrive well in a short time. That this improvement was due to the cod liver oil alone is shown by the result of treatment of the eight cases from the Children's Home in Copenhagen, described on p. 288. Amongst my earlier material there were two cases which showed that cod liver oil with ordinary boiled milk and milk pudding had a better and speedier effect than unboiled whole milk given alone. The same seems to have been true of a case where the child had had unboiled fresh milk and orange juice for some time. Though the general condition was considerably improved by this treatment, the eye complaint was only cured after the administration of cod liver oil.

The 15 cases treated at the State Hospital were given a diet corresponding to the children's age and development, designed to supply them with as much fresh milk as they could digest. The milk was always boiled. Three children under 6 months old had human milk at first. The boiled milk was good fresh milk heated to boiling point and then quickly cooled. The experiments on animals carried out in America have shown that the specific bodies will stand a short boiling but that they are destroyed by prolonged heating. The 
same apparently is true for cod liver oil. The product used was always the ordinary Norwegian "steamed medicinal cod liver oil." This has only been heated to $50^{\circ} \mathrm{C}$. It is possible that other preparations which have undergone a more drastic treatment will be found to have no specific effect at all, as by such a handling the lipoid bodies may have been rendered inactive.

The result of the treatment of the 23 cases here described was that only one died. The remainder recovered. The child that died had total necrosis of both corneae. The cause of death, which took place 11 days after entering hospital, was an attack of broncho-pneumonia. Only one of the 22 children which recovered became completely blind. On admission this child had complete necrosis of both corneae. Normal sight of both eyes was restored in the 13 cases which were taken in time. Normal sight of one eye was restored in five cases and three children were discharged with indifferent sight of both eyes. The results obtained were thus considerably better than in the earlier cases. This was due to the fact that the disease was generally recognised earlier. The treatment has proved so reliable that it is always possible to save the sight provided the treatment is started before the corneae have become necrotic.

Of the 15 children treated at the State Hospital during 1917 only one (a three months' old child with carbohydrate dystrophy) came from Copenhagen, the other children were from the country. The table below shows that the number of cases from the country and their distribution was very much as in 1916.

The children from the country nearly all came from the poorest and most destitute homes, those of labourers, herdsmen, outdoor servants and the poorest cottagers, and they nearly all bore evidence of extreme poverty and neglect. Almost all came from the country proper, and only a few from provincial towns. Most of them came from Zealand, but there were also cases from the other islands and from Jutland.

The main reason for the malnutrition of the children must undoubtedly in most cases be sought in the parents' want of sufficient means of subsistence. The high prices forced them to give the children the cheapest possible food,

\begin{tabular}{|c|c|c|c|c|c|c|c|c|c|}
\hline & \multirow[b]{3}{*}{ Total } & \multirow[t]{2}{*}{. } & \multirow[b]{3}{*}{$\begin{array}{c}\text { From } \\
\text { Copenhagen }\end{array}$} & \multicolumn{6}{|c|}{ Age of the patients } \\
\hline & & & & \multicolumn{3}{|c|}{ From the country } & \multicolumn{3}{|c|}{ From Copenhagen } \\
\hline & & $\begin{array}{l}\text { From the } \\
\text { country }\end{array}$ & & $\widehat{\begin{array}{c}2-6 \\
\text { months }\end{array}}$ & $\begin{array}{c}6-12 \\
\text { months }\end{array}$ & $\begin{array}{c}=> \\
1 \text { year }\end{array}$ & 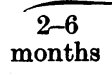 & $\begin{array}{c}6-12 \\
\text { months }\end{array}$ & $\begin{array}{l}\Rightarrow> \\
1 \text { year }\end{array}$ \\
\hline 1912 & 4 & 2 & 2 & - & 1 & 1 & 1 & 1 & - \\
\hline 1913 & 9 & 8 & 1 & 4 & 3 & 1 & 1 & - & - \\
\hline 1914 & 8 & 6 & 2 & 2 & 1 & 3 & 2 & - & - \\
\hline 1915 & 11 & 8 & 3 & 1 & 7 & - & 1 & 2 & - \\
\hline 1916 & 17 & 14 & 3 & 1 & 5 & 8 & 2 & - & 1 \\
\hline 1917 & 23 & 14 & 9 & 2 & 7 & 5 & 1 & - & 8 \\
\hline tal & 72 & 52 & 20 & 10 & 24 & 18 & 8 & 3 & 9 \\
\hline
\end{tabular}


and the cheapest is, as is well known, the poorest in fat. One would have thought it would have been comparatively easy to get unskimmed milk in the country. However, just the opposite seems to be the case. The parents always said that it was difficult to get unskimmed milk unless one had a cow oneself. All the unskimmed milk went to the dairies. It was easy, however, to get both centrifuged milk and buttermilk, both of which remained cheap, while the price of unskimmed milk kept on increasing.

The reason for the somewhat larger number of town cases in 1917 is entirely accounted for by the eight children from the Copenhagen Children's Home. It is significant that these cases occurred because the children in this Home during 1917 had been on a diet similar to that supplied in the poorest cottagers' homes, namely pasteurised skimmed, instead of whole, milk.

There are two other conditions besides diet which are of considerable importance for the development of xerophthalmia. These two factors are: the relation of xerophthalmia to the time of year and the effect of other infections on the appearance and course of the disease.

With regard to the influence of the seasons the accompanying Chart 4 shows that most of the cases appeared during the three months, March, April and May. The largest number occurred in May. Of the 23 cases during 1917, 18 occurred in this three-month period.

Of the 1917 cases there were eight in which, in addition to the eye complaint, the only abnormality was inhibition of growth. If there had been no opportunity of following these cases from the Children's Home over an extended period, so that the loss of weight and inhibition of growth could be observed, little beyond the eye trouble would have been discovered. In these uncomplicated cases the eye complaint appeared about the same time in May. This result can hardly be accidental; it has been true of the incidence of xerophthalmia year after year (Chart 4), and there must undoubtedly be some natural cause. In my earlier communication I pointed out that it could hardly be due to the diet. The children had had almost the same food both winter and spring. I then put forward the suggestion that it might be connected with the children's growth period.

Malling-Hansen, by his studies at the Deaf and Dumb Institute in Copenhagen, has shown that there exist quite definite periods of growth in children, and his results have been confirmed by Camerer and Schmid-Monnard. From these investigations it would appear that during the year there are three periods of growth as measured by increase in height, viz. a minimum, an intermediate, and a maximum period. The minimum period starts in August and lasts until the end of November. During this time children hardly grow at all. In the intermediate period from the end of November to the end of March, the children grow twice as much as during the minimum period. From the end of March up to well into August the growth amounts to two-anda-half times that of the minimum period. The growth period of children is 
therefore preeminently from November till August and is greatest in the months of spring.

In Chart 4 the occurrence of xerophthalmia in relation to the seasons is shown in company with Malling-Hansen's curve of the three periods of growth, and it will be seen how accurately they agree, the greatest number of cases of xerophthalmia coinciding with the maximum period of growth. If the cases of infants with carbohydrate dystrophy are excluded, all cases of xerophthalmia will be found to have occurred during the two periods of

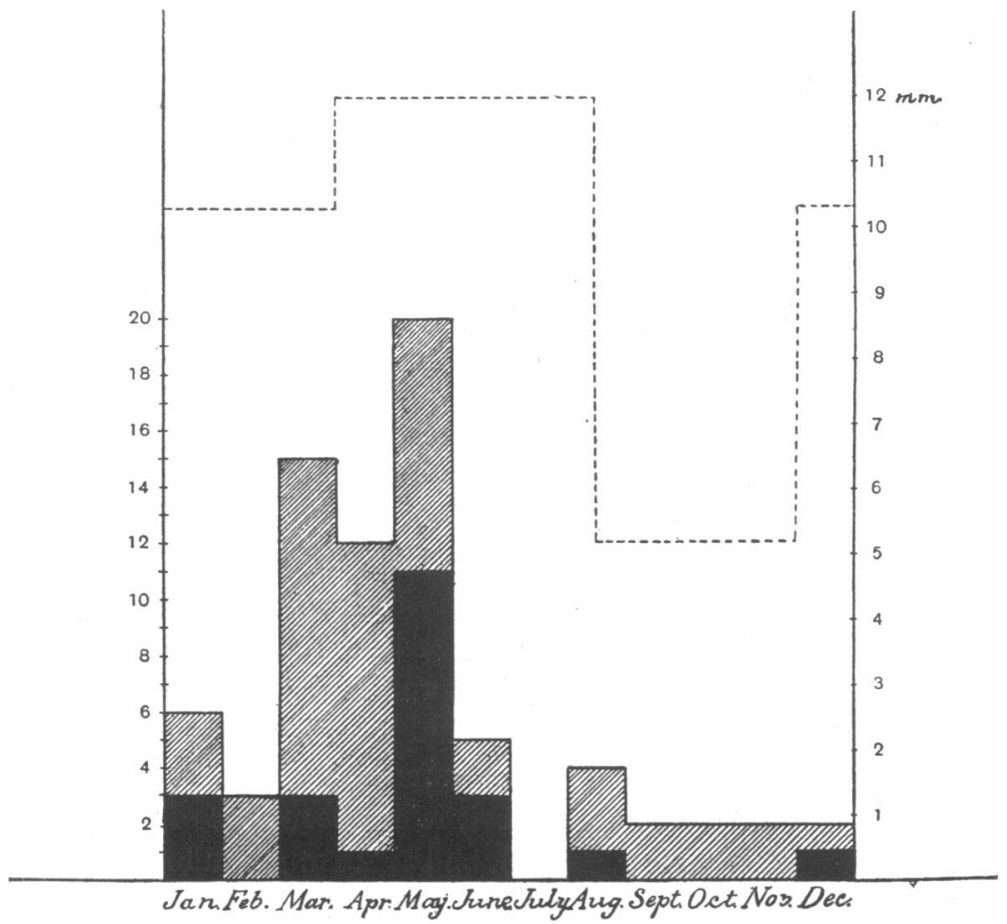

Chart 4. The broken line gives the seasonal periods of growth according to Malling-Hansen. The shaded columns record the seasonal incidence of xerophthalmia (admission to hospital) for 63 cases, 1911-1917.

The black columns give a similar record for 23 cases from 1917 onwards.

growth and none during the minimum period. Of the uncomplicated cases all are found to have occurred in the second month of the period of maximum growth.

These facts can be best explained by assuming that the specific lipoid bodies essential for growth are being continually used up while growth is taking place. One could easily imagine that the specific substance took part in the formation of new tissue or, what seems more probable, that the lipoid bodies were necessary for the glands on whose proper functioning growth depends. Funk holds this view with regard to the influence of vitamines on growth. 
As xerophthalmia is caused by the absence of bodies essential for growth, it is clear that the disease will predominate during that part of the year when the organism consumes the largest quantities of lipoid bodies, for its growth, i.e. during the maximum period for growth.

As already pointed out, the majority of my cases support this contention, particularly the uncomplicated ones. Some cases, however, appeared earlier, i.e. during the intermediate period of growth. In these cases there must be other causes which are also operative. This leads us to the other important aetiological factor: the influence of other infections on the appearance and course of xerophthalmia.

From a study of my cases it is evident that whenever xerophthalmia breaks out before the maximum period of growth, acute and chronic infections have always been present for some time, while in uncomplicated cases xerophthalmia occurs within the maximum period. The only exceptions are the rare cases of carbohydrate dystrophy in infants, but here the conditions of growth are probably quite different (Friedenthal). We see therefore that only those cases with a chronic infection make their appearance in advance of the usual time. This indicates that the infection contributes or predisposes to xerophthalmia.

Xerophthalmia may be cured by supplying the specific lipoid bodies. The same is the case with regard to the inhibition of growth. The children begin to thrive again when given cod liver oil. The cases following in the wake of other infections behave similarly. Clinical experience has shown that the only way of curing all these infections is by strengthening the children's general constitution by supplying the absent specific bodies in the form of cod liver oil, whole milk, eggs, etc. At the State Hospital no other treatment has been used and the infections were nearly always completely cured when the children were discharged.

The grave prognosis which previously obtained in cases of xerophthalmia was linked with this question of secondary infections. So serious indeed was the outlook that children, as was the case with young rats, died if a change to a proper diet was not made. The reason why young rats died is not explained but in the case of children the infections are the cause. It is absolutely characteristic of these dystrophic children, how little able they are to withstand infections and how quickly they die of a serious intercurrent infection.

It will be seen therefore that there are three aetiological factors responsible for the origin and the development of xerophthalmia:

Firstly, the diet, which does not contain, or at any rate is poor in the specific lipoid body or bodies.

Secondly, growth; xerophthalmia is found particularly in children, or animals who are growing.

Thirdly, antecedent infections of long duration. The explanation of this is uncertain, since no animal experiments have yet been brought to bear on the subject. It is, however, reasonable to suppose that the specific lipoid bodies 
are necessary for formation of antibodies against infections and that they are continuously used up in the process as in the case of growth. Antibodies may indeed be looked upon as a kind of internal secretion. Thus it will be easily understood that patients suffering from "Mehlnährschaden" and from the special form of dystrophy here elucidated, are extremely susceptible to all infections and have very little capacity for resistance.

This would explain why xerophthalmia in earlier days was discovered usually in the final stages of prolonged disease such as tuberculosis and typhoid fever. We also get an explanation of the well-known ancient clinical observation, which is certainly true, that foods such as whole milk, cream, egg, and cod liver oil are particularly important for children when they are growing most, just as they have been shown to be the best foods in the convalescent stages after infections and in the treatment of chronic tuberculosis.

\section{SUMMARY.}

1. There are fats which are indispensable for children because they contain specific bodies, essential for normal growth.

2. If these lipoid bodies, termed "fat soluble A bodies" by McCollum, are absent from the food for a long time, an inhibition of growth will occur and the conditions which I have termed Dystrophia alipogenetica will finally appear. This condition involves a great susceptibility and lowered resistance to all infections and often leads to xerosis of the conjunctivae and corneae associated with night blindness. The xerosis has a great tendency to result in keratomalacia. In its first stage xerophthalmia resembles a slight conjunctivitis; the children develop photophobia, their eyes are red and there is a slight secretion.

3. Xerophthalmia generally occurs in spring, the time when growth is at its maximum.

4. The disease is most frequent amongst the children of the poorest country folk and is always due to an unsuitable artificial diet, generally the replacing of whole milk partly or completely by centrifuged milk, butter milk or concoctions of flour. It may appear in children who have received whole milk and cream, but in that case the milk and cream have been boiled for too long a time or have been subjected to other kinds of drastic treatment which have destroyed the specific lipoid bodies.

5. Xerophthalmia is easily cured when recognised in time. The best treatment is cod liver oil, but whole milk and probably cream, butter, eggs and other fats containing the specific lipoid bodies are also curative. It is important to remember that these foods should only be subjected to the ordinary short boiling.

6. The disease is fairly common in Denmark, apparently more so than in other countries. It is, for instance, practically unknown in Sweden and Norway. According to Mori's statistics it used to be rare in Germany. The 
reason for its being so frequent in Denmark is probably partly due to the fact that this country exports most of its dairy produce, especially butter.

7. Many of the cases of blindness and leucoma attributed to eye complaints during infancy, are perhaps due to xerophthalmia. Of late it has been said that blindness amongst children in Denmark is increasing while gonorrhoeal ophthalmia in new born infants at the maternity hospital is decreasing. Ophthalmo-blenorrhoea has been the cause of blindness in very few of the recent admissions to the blind institute, all of which supports my contention that xerophthalmia is the actual cause of the large number of blind children in Denmark.

\section{REFERENCES.}

BLOch, C. E. (1918). Rigshospitalets Borneafdeling Meddelelser. II.

Czerny, A. and Kallar, A. (1906). Des Kindes Ernährung etc., Leipzig.

Friedenthad, H. (1913). Über Wachstum. Ergebnisse d. inn. Med. und Kinderheilk. xr.

Funk, C. (1914). Die Vitamine, etc., Wiesbaden.

JENSEN, E. (1903). Xerophthalmia amongst children. Hospitalstidends.

LANGSTein and Ederstein (1917). Zeitschr. f. Kinderheilk. xvr.

McCollum and Davis (1915). Journ. Biol. Chem. Xx, XXI, XXIII.

MoCollum and Simmonds (1916). Ibid. xxIv, xxv.

- (1917). Ibid. xxxII.

Maluing-Hansen (1886). Periods in the growth of children and in the sun's heat, Copenhagen.

MoRI, M. (1904). Über der sogenannten "Hikan," etc. Jahrb. d. Kinderheilk. LIx.

Osborne and Mendel (1914). Journ. Biol. Chem.

PitZ and Kenneedy (1916). Ibid. xxiv, xxv.

Rönne, R. (1916). Über die Aetiologie und Behandlung der Keratomalacia. Klinische Monatschrift f. Augenheilk.

STEPP, W. (1917). Ergebnisse d. inn. Med. u. Kinderheilk. xv.

TshrHARA, S. (1913). Zur Aetiologie der idiopath. Hemeralopie bezw. Xerosis conjunct. Klin. Monatschr. f. Augenheilk.

\section{APPENDIX. \\ OBSERVATIONS ON XEROPHTHALMIA IN DENMARK DURING 1918 AND 1919.}

From Table I above and Chart 5 it will be seen that there is a sharp rise in the number of cases from year to year right up till 1918. It is particularly during the hard times consequent upon the war, in 1915, 1916, and 1917, that the cases are so frequent. If we now consider the districts the children came from, we find there are 52 from the country and only 12 cases from Copenhagen if we except the eight cases from the Children's Home. All the most serious cases came from the country, having arisen in connexion with a diet composed principally of centrifuged milk, bread, potatoes, and margarine, and it is these cases which have increased so markedly during the war.

That there have been more patients from the country is due to the fact that all through the war care has been taken that there was a comparatively 
plentiful supply of fresh milk in Copenhagen for children and that the cost was reasonable even for poor people. In the country the conditions were difficult as already mentioned.

During 1918 a change suddenly occurred, the number of cases treated by me falling from 23 in 1917 to 1 in 1918.

The single case which was admitted to the State Hospital in 1918 had only an exceedingly slight degree of xerosis of the conjunctivae. It was an emaciated infant with marked carbohydrate atrophy, arising from a diet of barley water during a long period.

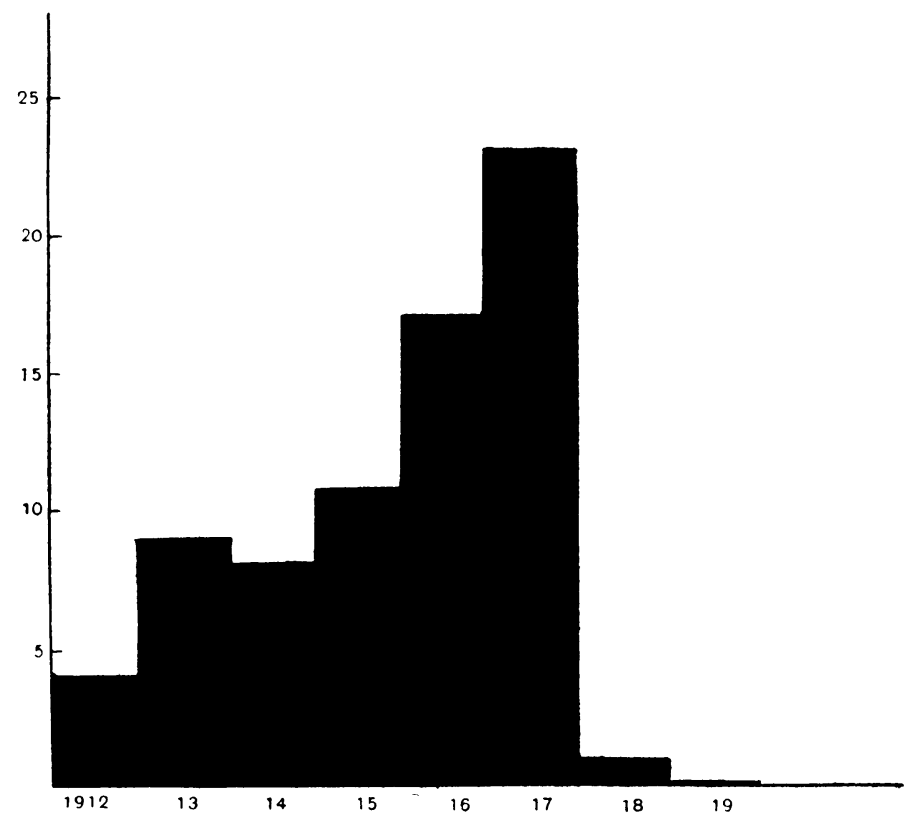

CHART 5. Recording the number of cases of xerophthalmia admitted to the State Hospital, Copenhagen, 1912-1919.

There have been no cases treated in the State Hospital in 1919 (up to July 1st); from the experience of previous years it is not to be expected that any cases will arise now that the season of the year is past when the disease usually appears.

It is impossible that this decrease can be due to the fact that cases in 1918 and 1919 were being treated at other hospitals than the State Hospital. This is the only civil hospital which is owned and managed by the Danish Government and it therefore receives patients from the whole country, from towns as well as country districts, and deals preferably with difficult and serious cases. Thus the diseases which are treated in the course of the year at the State Hospital are always a good sample of the serious affections which are spread throughout the whole country (acute infectious diseases excepted).

The sudden decrease in the number of cases shows therefore, that after 
being a rather frequent and serious condition, the disease had suddenly become uncommon or mild.

The Ophthalmological Society of Copenhagen has this year (1919) undertaken a statistical investigation of the incidence and distribution of xerophthalmia in Denmark, through Dr O. Blegad. The work is not yet finished, but it already appears that about 400 cases have been discovered from 1908 to 1917 (inclusive), and that the number has risen considerably during the war. For the year 1918 only a very few cases (six to eight) could be collected and none at all for 1919. This corroborates my contention that xerophthalmia was formerly a rather common disease in Denmark, that it increased greatly during the war and practically ended in 1917.

The reason of this cannot be that the period of scarcity became less acute during 1918 and 1919. The opposite is the case, as is well known. When the German submarine blockade became established in February, 1917, the import of fodder for cattle was completely stopped. The result was that the production of milk was more reduced than before and prices for fresh milk, cream and butter reached hitherto unknown heights.

It is possible that the decline of the disease in 1918 may to a small extent be accounted for by the appearance of my articles on the subject in 1916, 1917, and 1918, and the discussion to which they gave rise. Every Danish doctor had his attention drawn to this disease. This may have played a part especially with regard to those cases which arose from an excessive diet of carbohydrates, in that the doctors may have changed the food in time. It cannot however apply to the large number of severe cases from the poorest homes,-where the children had lived on centrifuged milk, margarine, lard, bread, potatoes and the like, because in these cases marasmus is often the only manifestation of the disease until the point when the eyes are attacked.

The only possible explanation seems to be the radical change of food which took place after December, 1917, for the whole population, particularly, however, for the poor. From February, 1917, the German U-boat blockade put an end to the importation of fodder for cattle, and of all fat-stuffs, including raw products for the production of margarine. Consequently pigrearing became limited and the manufacture of margarine ceased completely in the course of a short time. As previously pointed out, lard, meat and above all margarine are the fatty foods on which the greater portion of the Danish population live. When the supply of margarine and lard failed in 1917 and no more was forthcoming, butter was the only fat left. The blockade was also responsible for a largely decreased output of butter and prices became impossible for the masses of the people. Thus it became necessary for the State to take over control of all butter. From December 21, 1917, butter was rationed so that everybody, adult and child, was entitled to receive $250 \mathrm{gms}$. a week, and it was sold at such a low price that all could buy it.

From that moment everyone ate butter instead of margarine and since then there has been no xerophthalmia in Denmark. 
It will be seen how this great dietetic experiment involving a whole nation, accurately agrees with the American and English animal experiments and with my earlier clinical observations.

On the other hand it is impossible with certainty to throw any light on the extent to which change of diet in 1918 and 1919 affected the two other conditions associated with xerophthalmia in young children, viz.: dystrophy and the reduced power of resistance towards infections. In addition to change of diet there are so many other circumstances which must have had an influence on the morbidity and mortality of these two years. So much however can be said that the morbidity and mortality in 1918 and 1919 have been comparatively slight taking into account the great influenza epidemic. Now that the war is over, the manufacture of margarine will be started again and the rationing of butter will cease, so that, on account of its cheapness, margarine will supersede butter as before. It is therefore to be feared that next spring this disease of malnutrition and the disastrous ophthalmic condition will occur again amongst the children of the poorer people in Denmark.

\section{EXPLANATION OF PLATES II-IV.}

PLATE II.

Fig. 1. Atrophy with keratomalacia, dry scaly skin, stiff neck, arms in the "paw position," infant extremely impoverished and wretched. Type 1.

Fig. 2. Anna, M. J. Three months old. Carbohydrate dystrophy with ocdema. Type 2.

Fig. 3. Jörgen, J. Two years old. Dystrophy and xerophthalmia with total necrosis of both corneae. The disease arose from feeding with centrifuged milk. Type 3.

\section{PLATE III.}

Fig. 4. Gunner Willy N. After recovery. The child can see well; right eye almost normal with a little spot situated upwards and inwards; left eye partly staphylomatous.

Double-sided keratomalacia with complete necrosis of left cornea ; right cornea generally hazy, with ulceration on its upper and inner aspect.

The disease arose in a 16 months' infant after feeding from the age of six months with centrifuged milk, milk pudding, oatmeal porridge, etc.

Treated with cod liver oil, fresh milk, and milk pudding.

Fig. 5. Leo A. After recovery. The child can see a little with the right eye which is partly leucomatous. The left eye is wasted.

Double-sided keratomalacia, total necrosis of left cornea with perforation and expulsion of lens, etc.; half of the right cornea necrotic, also with perforation.

The disease appeared in a 14 months' infant after feeding with centrifuged milk, rusks, etc. (The child never received any fresh milk.)

Treated with cod liver oil, fresh milk, and milk pudding.

\section{PLATE IV.}

Fig. 6. Yrsa N. After recovery. The child can see with the right eye which is almost normal, the left eye being for the most part leucomatous.

Double-sided keratomalacia with total necrosis of the left cornea and less necrosis of the right, in an infant three months old.

The disease arose after about two months' feeding with oatmeal.

Treated with cod liver oil, human milk, and milk with other things.

Fig. 7. Vilfred $H$. After recovery. The child is blind, left eye wasted, right eye staphylomatous.

Double keratomalacia, with widespread necrosis of corneae, in a two months' old child.

The disease arose after two months' feeding with oatmeal gruel.

Treated with human milk. 
JOURNAL OF HYGIENE, VOL. XIX. NO. 3

PLATE II

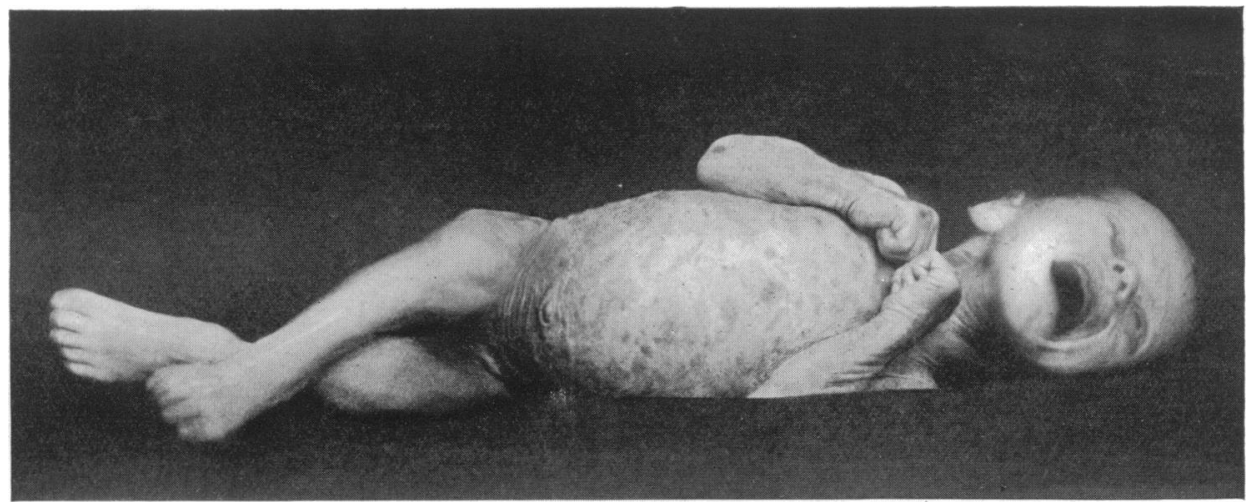

Fig. 1

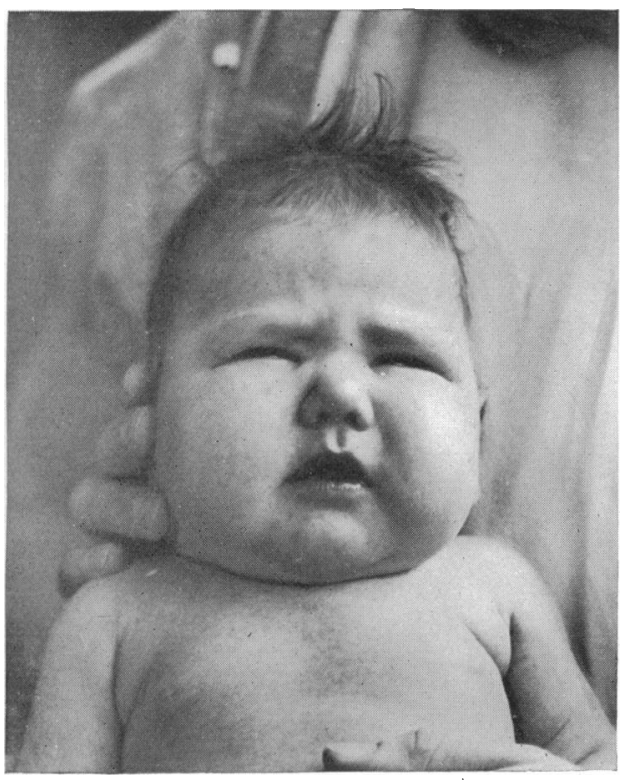

Fig. 2

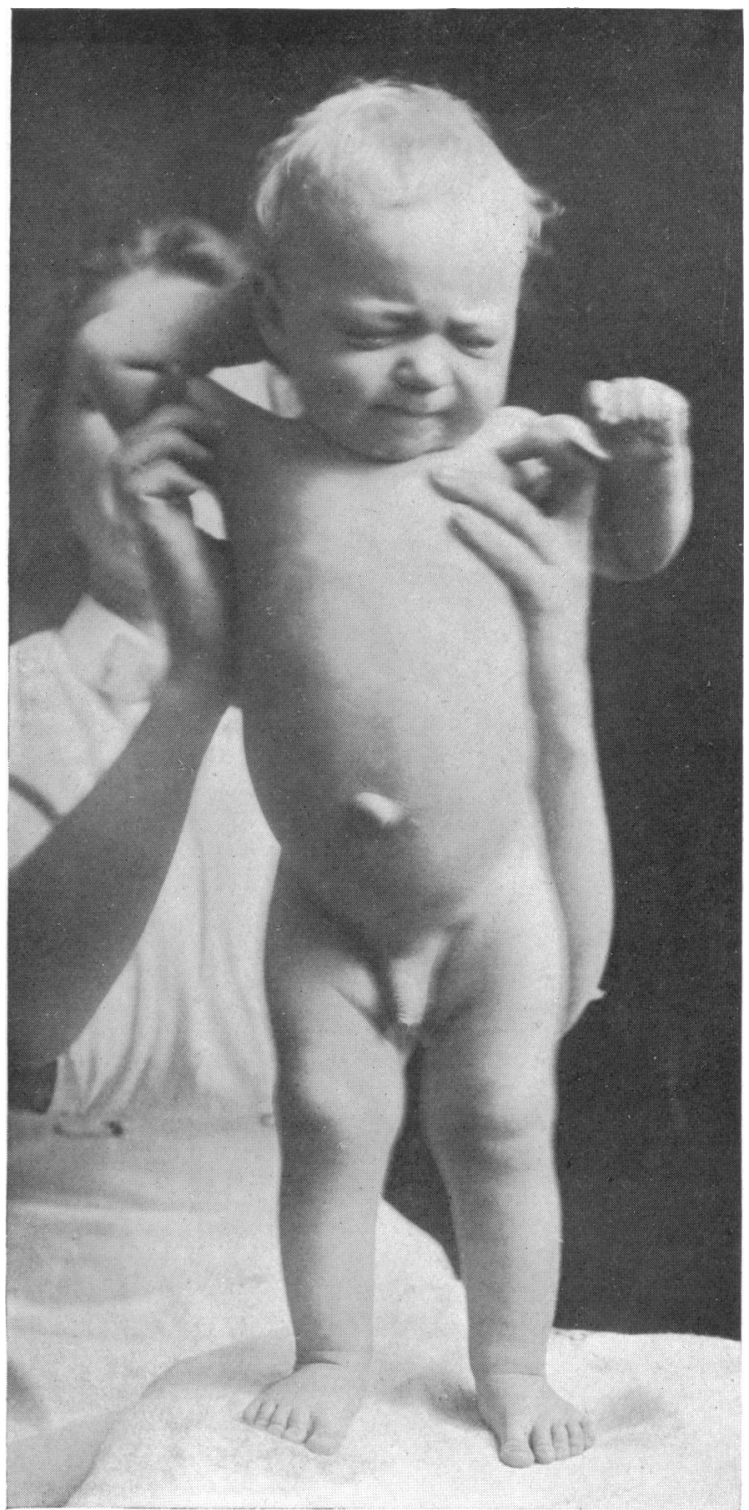

Fig. 3 
JOURNAL OF HYGIENE, VOL. XIX. NO. 3

PLATE III

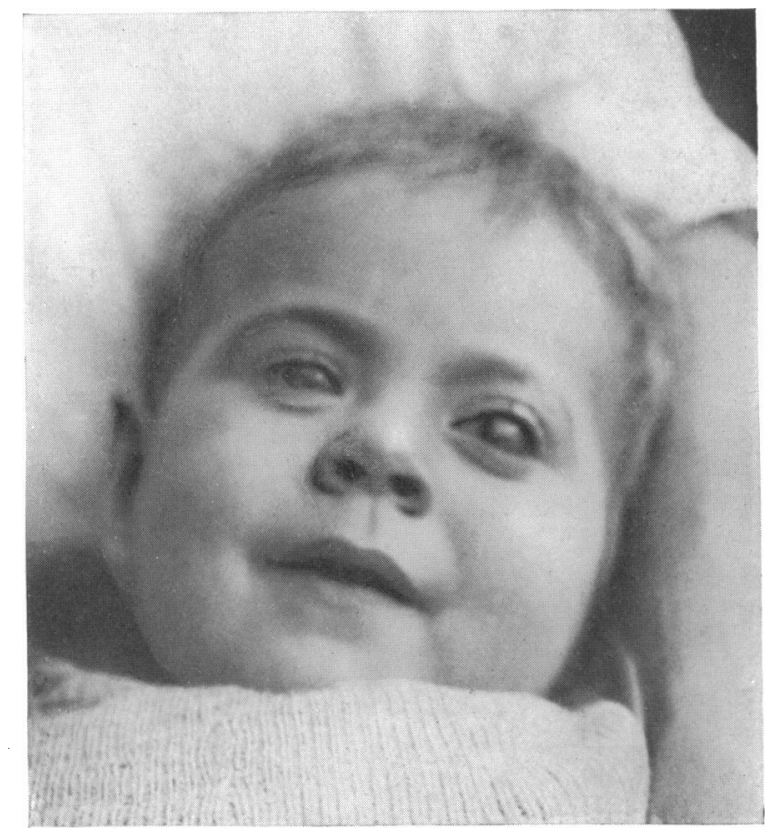

Fig. 4

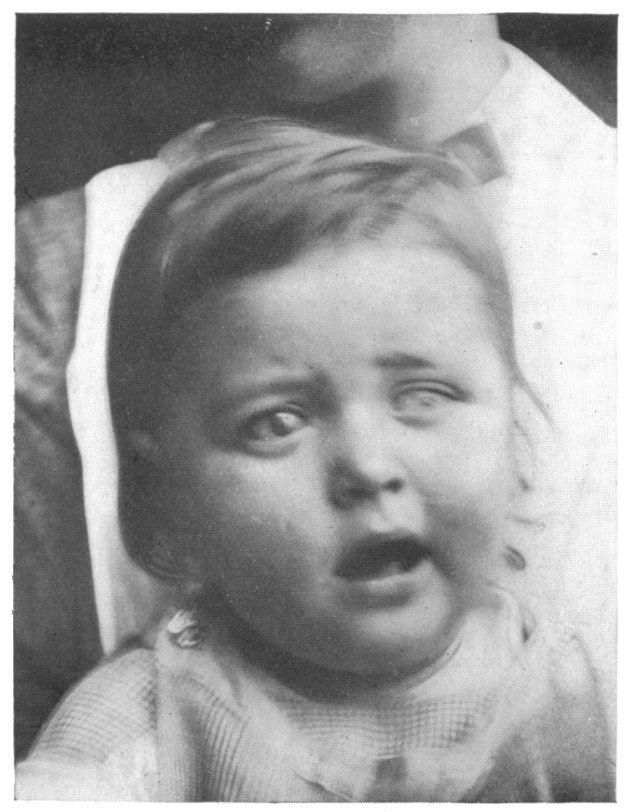

Fig. 5 
JOURNAL OF HYGIENE, VOL. XIX. NO. 3

PLATE IV

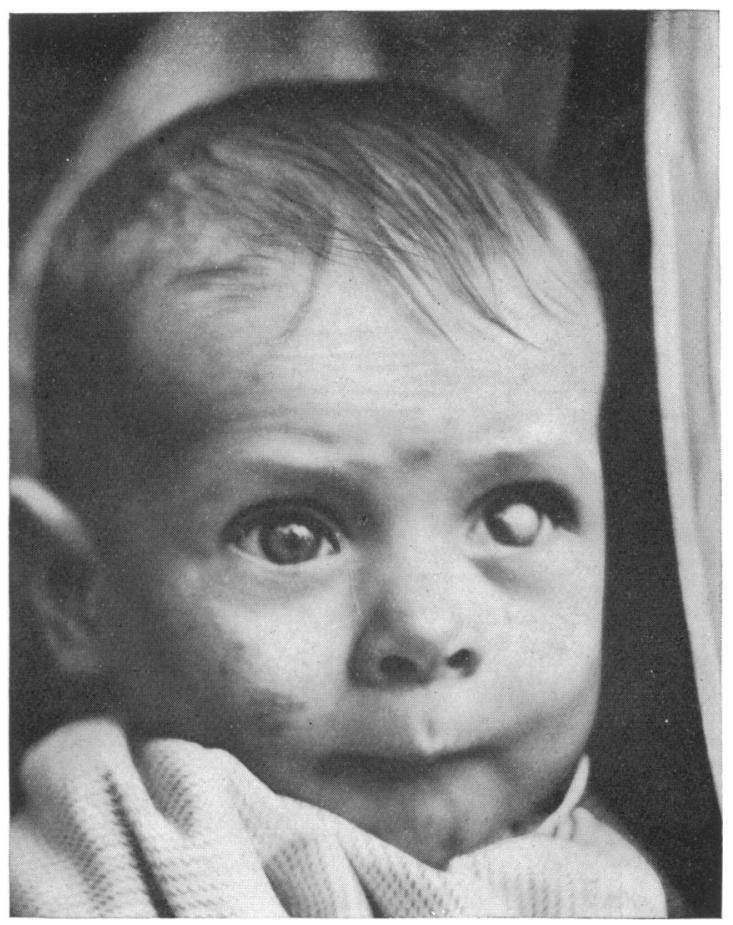

Fig. 6

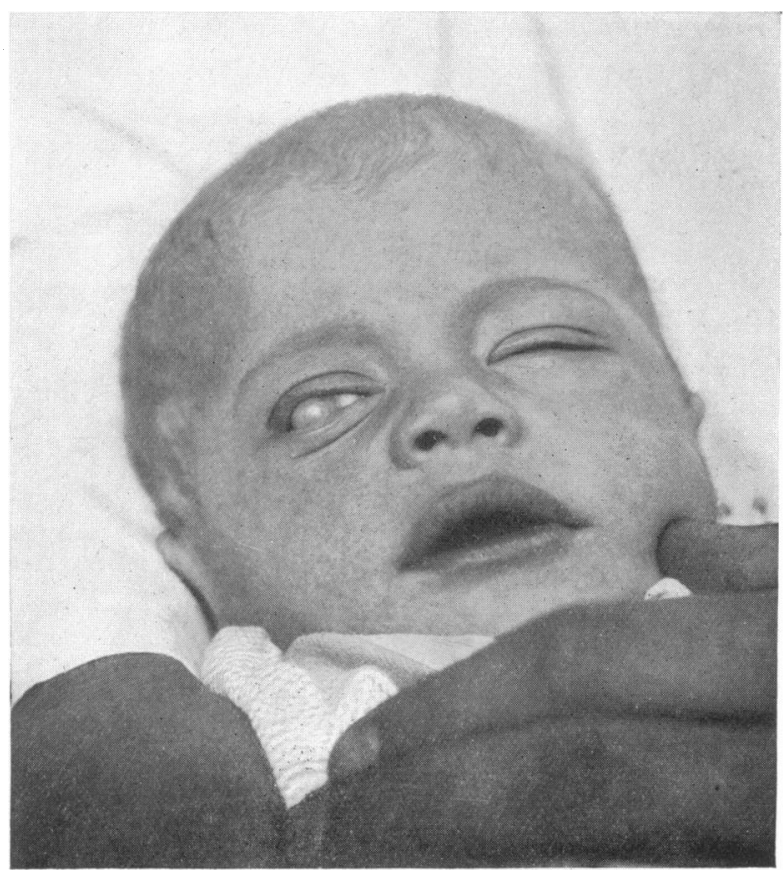

Fig. 7 